\title{
Biografias e autobiografias como fontes de informação e memória
}

\author{
Biographies and autobiographies as sources of information and memory
}

\begin{abstract}
Rita de Cássia Gonçalves
Mestra em Ciência da Informação pelo Programa de Pós-Graduação em Ciência da Informação da Universidade Federal de Minas Gerais - UFMG, Brasil.

E-mail: rita.goncalves2007@hotmail.com
\end{abstract}

Fabrício José Nascimento da Silveira Doutor em Ciência da Informação pela Universidade Federal de Minas Gerais - UFMG, Brasil. Professor da Escola de Ciência da Informação da Universidade Federal de Minas Gerais - ECI/UFMG, Brasil. E-mail: fabrisilveira@gmail.com

\section{Resumo}

Este artigo tem por objetivo explorar a dupla função do gênero biografia: fonte de informação e memória. Amparado em revisão bibliográfica inscrita em perspectivas multidisciplinares, buscou-se apreender as especificidades do gênero biográfico e caracterizar as produções dele derivadas - notadamente as biografias e autobiografias - tanto como fontes de informação quanto como recursos sociais de produção e disseminação de memórias individuais, sociais e históricas. Como resultado, pontua-se que os escritos autobiográficos e as biografias, por estarem intimamente imbricados ao "espírito de sua época", não devem ser percebidos como uma narrativa caracterizada pela sucessão de eventos encadeados cronológica e linearmente, mas, antes, como fruto de escolhas, negociações e contingências que, em seu conjunto, modulam uma imagem razoavelmente delineada de determinado sujeito e de suas experiências vivenciais. Nesses termos, podem nos informar sobre as circunstâncias históricas, políticas, culturais e sociais de uma época, tanto quanto sobre as singularidades de uma vida privada, seja ela de pessoas comuns ou daqueles que se tornaram "heróis nacionais" ou, ainda, modelos de virtude.

Palavras-chaves: Biografia. Autobiografia. Biblioteconomia. Fontes de informação. Memória.

\begin{abstract}
This article aims to explore the biography genre in its dual function: source of information and memory. Supported by a bibliographic review inscribed in multidisciplinary perspectives, we sought to apprehend the specifics of the biographical genre and characterize the productions derived from it - notably the biographies and autobiographies - both as sources of information and as social resources for the production and dissemination of individual, social and historical memories. As a result, it is pointed out that autobiographical writings and biographies, as they are intimately imbricated to the "spirit of their time", should not be perceived as a narrative characterized by the succession of events linked chronologically and linearly, but, rather, as the result of choices, negotiations and contingencies that, as a whole, modulate a reasonably delineated image of a certain subject and his living experiences. In these terms, they can inform us about the historical, political, cultural and social circumstances of an era, as well as about the singularities of a private life, be it of ordinary people or of those who have become "national heroes" or, still, models of virtue.
\end{abstract}

Keywords: Biography. Autobiography. Librarianship. Information sources. Memory. 


\section{Introdução}

Em linhas gerais, as narrativas biográficas são caracterizadas como a descrição de uma vida, não importando o quão célebre o sujeito biográfico tenha sido. Escrever sobre uma vida é atividade difícil e minuciosa dado exigir tanto um trabalho colaborativo quanto a "flexibilização das fronteiras disciplinares" (CARVALHO, 2008, p. 30). Assim observado, independente se ficcionais ou factuais, essas obras preenchem o imaginário do leitor que busca conhecer o indivíduo cuja vida se deslinda em forma de testemunho ou de relatos em terceira pessoa.

A despeito disso, as transformações epistêmicas em torno do gesto biográfico quase sempre impõem dificuldades àqueles que o exercem. Isso se dá, em primeiro lugar, porque é fácil se cair na tentação de cogitar conferir unicidade a vidas que são, em essência, contraditórias, ambivalentes e localizadas em tempos e espaços específicos. Em segundo lugar porque, não raro, buscamos dar visibilidade, ainda sob influência de uma histoire événementielle, a sujeitos que em seu contexto alcançaram certo destaque, como se a importância de uma pesquisa biográfica estivesse limitada ao registro e constatação da proeminência do objeto, da história de vida selecionada. Talvez seja em função disso que François Dosse (2015, p. 12) afirme que a biografia se situa "entre ficção e realidade histórica", equilibrando-se entre uma "verdade histórica e uma verdade literária” (LORIGA, 2011, p. 18). Conjunção que, contemporaneamente, fez com que as biografias ganhassem espaço enquanto documento no âmbito de diferentes áreas do conhecimento: história, sociologia, educação, literatura, só para citarmos algumas.

Dialogando com o historiador francês, Leonor Arfuch (2010) considera que "o espaço biográfico 1 " é múltiplo e variado, compondo-se de inúmeras narrativas entre as quais destaca: biografias autorizadas ou não, autobiografias, testemunhos, memórias, histórias de vida, diários íntimos, correspondências, cadernos de notas, autoficções, entrevistas midiáticas, romances e ensaios. Atentando também para a expansão do espaço biográfico na atualidade, Arfuch assinala de forma clara uma crescente expectativa e uma frenética exaltação dos espectadores por narrativas vivenciais. Expectativas que não se voltam mais e tão somente para as biografias

\footnotetext{
${ }^{1}$ Para Leonor Arfuch (2010) o espaço biográfico não diz respeito, única e exclusivamente, ao conjunto de gêneros textuais correlacionados à escrita de si, mas, antes, às afinidades que eles mantêm, as quais conformariam um espaço por ela definido como "horizonte de inteligibilidade" (ARFUCH, 2010, p. 16). Assim, “a um conjunto de informações já tradicionalmente associadas às narrativas que têm como principal objeto o próprio autor que as escreve, a contemporaneidade agrega outras, ampliando o escopo disso que podemos entender como "espaço biográfico": são entrevistas, testemunhos, talk shows e reality shows, enfim, uma série de novas formas narrativas que se desenvolvem no ambiente midiático e tecnológico". (SILVA; MOREIRA, 2016, p. 08).
} 
heroicas, posto recaírem, na grande maioria dos casos, sobre os "anti-heróis" e suas vidas corriqueiras. Nesses termos, se em sua gênese o trabalho biográfico esteve ligado às grandes figuras públicas e aos elogios memorialísticos feitos a reis, santos, políticos, intelectuais e militares, agora faz-se perceptível um crescente interesse pela vida de pessoas comuns.

Não por acaso, no espaço corrente das instâncias e domínios de produção do conhecimento, as narrativas biográficas têm se consolidado como importantes fontes de informação e de memória. Constatação que tem como ponto de referência o fato dessas obras, na grande maioria dos casos, conseguirem transpor a esfera da individualidade para se consolidarem em documentos sintetizadores de uma época, de um lugar, de uma instituição ou mesmo de um sistema de pensamento.

Tendo isso em vista, o presente artigo se propõe a discutir o conjunto de qualificadores que fazem das biografias e autobiografias fontes primárias e secundárias de informação, refletindo, também, acerca de seus atributos enquanto documentos agregadores e difusores de conhecimento e memória. Para tanto, estabelece-se um diálogo com estudos e formulações provenientes de diferentes campos do saber, especialmente a história, a literatura, a filosofia, a sociologia, a biblioteconomia e a ciência da informação.

Subdividido em duas seções principais, o texto que se segue confere destaque, primeiramente, aos referentes históricos e conceituais que assinalam uma evolução do gênero biográfico/autobiográfico, destacando-se os principais elementos que caracterizam essas obras como documentos de memória. Na segunda seção são apresentados o conjunto de tipologias e propriedades definidoras de uma fonte de informação para, em seguida, sintetizarmos os qualificadores essenciais que fazem das biografias e autobiografias fontes de informação. Dito isso, iniciamos nossa empreitada investigando qual é a natureza do gênero biográfico. 


\section{Biografias e autobiografias: entre o real, o ficcional e a memória}

Dizer o que é uma biografia e uma autobiografia não se constitui, em si, uma novidade acadêmica, posto o assunto ser recorrentemente abordado em diversos campos do conhecimento - a história, a filosofia, a literatura, a antropologia, a biblioteconomia entre outros -, condição que acentua sua importância enquanto gênero narrativo e a interdisciplinaridade metodológica que circunscreve seus múltiplos modos de elaboração, estudo e apreensão. Isso se dá porque tais modalidades textuais são, desde sua gênese, estruturadas a partir de um complexo processo de mapeamento e de urdidura de dados, acontecimentos, relatos testemunhais e biografemas ${ }^{2}$ que, ao serem agregados entre si, acabam por retratar tanto uma vida específica quanto por descrever relações humanas, padrões de comportamento social e dinâmicas culturais singulares a um momento histórico ou a um lugar.

Não sem razão, ao se interrogar sobre a natureza da biografia e do gesto autobiográfico, Sylvia Molloy (2003) nos diz que tanto uma modalidade textual quanta a outra resulta da arte de contar a história de uma vida e que sua potência interpretativa está diretamente vinculada àquilo que é possível se extrair dessa história. Tendo por referência essa assertiva, se por longa data a produção de biografias centrou-se na descrição cronológica da existência e dos feitos de um sujeito singular, mais contemporaneamente a escrita biográfica/autobiográfica se faz mediante "uma espécie de etimologia do minúsculo" (COSTA, 2010, p. 29), a partir da qual cada fragmento evocado acena para aquilo que uma vida tem de mais vigoroso: "seu movimento de criação e de recriação de mundos" (COSTA, 2010, p. 29).

Movimento que, por sua vez, é executado de forma distinta pelo biógrafo e por aquele que produz um relato sobre si, uma autobiografia. No primeiro caso a escrita é feita, geralmente, por um pesquisador profissional que coleta, interpreta e divulga informações factuais e/ou ficcionais sobre alguém. Por sua vez, a autobiografia expressa-se como um relato pessoal, um testemunho concebido por indivíduos que se propõem a dividir sua intimidade e suas experiências com o público. À parte tal diferenciação, essas duas maneiras de se contar a história de uma vida possuem uma longa tradição histórica e desdobram-se em uma profusão

\footnotetext{
${ }^{2}$ De acordo com Costa (2010, p. 05), “o surgimento do biografema acompanha uma mudança de abordagem em relação às próprias vidas biografadas, acarretando num novo tratamento biográfico por parte das disciplinas. Tratase de outra postura de leitura, de seleção e de valorização de signos de vida. Ao invés de percorrer as grandes linhas da historiografia, a prática biografemática volta-se para o detalhe, para a potência daquilo que é ínfimo numa vida, para suas imprecisões e insignificâncias". Constitui-se, portanto, em outro tratamento para aquilo que "a cultura nos oferece acerca do autor (através dos livros, fotos, manuscritos, filmes, entrevistas, documentos, etc): a relação biografemática faz uso deste material, porém, toma-o compósito de signos soltos, prontos para pontilharem outros rostos, culminando em novos jogos de mentiras e verdades" (COSTA, 2010, p. 29).
} 
de estilos narrativos os quais, nas palavras de Jacques Le Goff, constantemente reinventam a escrita biográfica, livrando-a "dos bloqueios em que falsos problemas a mantinham". (LE GOFF, 2014, p. 21).

Afirmativa que se torna melhor apreensível quando recuamos no tempo e recuperamos indícios metodológicos, discursivos e funcionais vinculados à evolução histórica dos modos de se produzir obras biográficas e autobiográficas. Atentando para isso, é possível indicarmos que, enquanto gênero narrativo, a biografia surge na Grécia e que, em sua forma mais antiga, os historiadores concentravam-se em descrever "vidas notáveis". Por conseguinte, os autores dessa tipologia de texto também deveriam ser "sujeitos célebres", a exemplo de Homero, Plutarco e Suetônio. Ainda no Mundo Clássico, mas agora no contexto romano, esse quadro não se mostrou diferente, uma vez que importantes poetas, filósofos e historiadores se empenharam em garantir viva a memória de outros homens ilustres. Tendo por base esse preceito da notoriedade, o gênero biográfico desenvolveu-se portando o objetivo de "designar uma obra verídica, fundada numa descrição realista, por oposição a outras formas antigas de escritura de si que idealizavam o personagem e as circunstâncias de sua vida (tais como o panegírico, o elogio, a oração fúnebre e a hagiografia). (LORIGA, 2011, p. 17).

Somente no século XVIII esse estilo de se produzir relatos biográficos foi transformado graças à validação da subjetividade como marca referencial de uma possível "garantia biográfica". Foi Jean-Jacques Rousseau quem primeiro delineou, de acordo com Leonor Arfuch (2010), a especificidade do gênero autobiográfico na modernidade ao entrelaçar em suas Confissões distintas modalidades de escritas de si: diários íntimos, correspondências e memórias. Com isso, ao pretender mostrar a seus semelhantes um homem em toda a verdade de sua natureza por meio de um "eu" revelado como sujeito histórico, Rousseau evoca experiências e "verdades" que deseja compartilhar sinceramente, sem disfarces, expondo suas enfermidades, errâncias, indignidade, mas, também, sua generosidade. Para tanto, retira de si qualquer máscara que possa se interpor como obstáculo à exposição de "todos os seus movimentos afetivos" (STAROBINSKI, 2011, p. 247). Diante de tal pretensão, torna-se indispensável que Rousseau estabeleça um diálogo claro, em tom confessional, com seus leitores, dando-lhes a conhecer sua alma, seu coração e sua consciência. Com e depois de Rousseau o gesto autobiográfico insinua-se como prática de "afirmação identitária e de (re)construção das subjetividades" (CARVALHO, 2008, p. 19-20). 
Contudo, Philippe Lejeune (2014) ressalta a impossibilidade de se revelar totalmente a "verdade de uma vida". Isso significa que a autobiografia não se limita à história daquele que expõe seu testemunho. Em outros termos, a vida de uma pessoa, por mais solitária que seja, é sempre marcada por inúmeros contatos com o mundo exterior, e é nesses intervalos que a intimidade exposta em uma autobiografia nos permite conhecer o mundo no qual habita certo narrador, possibilidade que enseja uma espécie de "consumo viciante da vida dos outros" (ARFUCH, 2010, p. 61). Não sem razão, esse gênero narrativo se tornou uma espécie de best seller do século XVIII.

No entanto, ainda nas primeiras décadas do século XIX os textos biográficos e autobiográficos foram definidos como um "subgênero" da prática historiográfica, classificação que diminuiu o seu prestígio entre os leitores. Ancorado em premissas positivistas, o fazer biográfico foi investido da tarefa de historicizar e edificar apenas a vida de "grandes homens", vultos caros à pátria e à nação. Nesse cenário, historiadores e biógrafos "preteriram as trajetórias individuais em favor das investigações macroorientadas, estruturais, quantitativas, de longa duração". (SCHMIDT, 2000, p. 50). Ao procurar afirmar sua cientificidade aproximando-se da história e afastando-se da literatura, a biografia se viu confinada a uma situação subserviente: selecionava-se personagens proeminentes ou transformava-os em figuras de proa. Escolhas que explicam, em ampla medida, porque a escrita ou a narrativa da própria vida foi qualificada como um hábito mantido por pessoas pertencentes à classe dominante.

No entanto, à medida que as discussões sobre os processos de individualização ganharam evidência no âmbito das ciências humanas e dos estudos literários, novos olhares interpretativos foram impostos sobre os usos e abusos da memória, inclusive da memória biográfica. Tributária desses "novos olhares", a Idade Hermenêutica da biografia ${ }^{3}$ promoveu,

\footnotetext{
${ }^{3}$ François Dosse (2015, p. 122), ao observar que "o gênero biográfico encontra-se na transversalidade dos saberes", aponta, de forma paralela, que essa transversalidade pode ser visualizada nos três grandes momentos que demarcam a evolução histórica do gênero, quais sejam: a Idade Heroica, a Idade Modal e a Idade Hermenêutica. Resumidamente e segundo o autor, no contexto da Idade Heroica os escritos biográficos estavam imbricados ao gênero histórico. Assim, a biografia era entendida como obra destinada a salientar as qualidades do herói: a coragem, os sacrifícios, a guerra. Com isso, o sujeito biografado era o protagonista de uma vida que lhe exigiu ações edificantes e exemplares, razão pela qual esse herói tramitava na literatura entre o discurso de verdade do historiador e a criatividade da forma biográfica, posto que seu intuito também era privilegiar o imaginário dos leitores. Posteriormente, o historiador aponta que a Idade Modal da biografia valoriza a autonomia da história e converte o ser humano em objeto de investigação factual. Com isso, os escritos biográficos e autobiográficos passaram a ser considerados um gênero impuro, sendo reduzidos à categoria de "historietas". Isso se deu em um momento no qual as ciências sociais, alicerçadas na filosofia positivista, primavam pelo comportamento observável e previsível dos seres humanos. No último estágio desse esquema organizativo, a Idade Hermenêutica, o foco recai sobre a pluralidade das identidades. Privilegia-se, portanto, um movimento de retorno ao indivíduo e à sua singularidade.
} 
na passagem do século XIX para o XX, uma nova forma de se observar e de se relatar os fenômenos humanos. A partir disso, o fazer biográfico se viu obrigado a buscar respostas para duas questões concretas: quais seriam, então, as características necessárias para que um indivíduo tivesse sua vida narrada? Que motivações alguém teria para escrever sobre a vida de outrem ou sobre si próprio?

Atravessado por essas inquietações, o fazer biográfico contemporâneo tem se ocupado, contingencialmente, com elementos de cunho psicológico e análises contextuais reveladores tanto de uma dimensão histórica - das vicissitudes de uma época ou das realidades políticas, sociais e culturais de determinado lugar - quanto dos desejos, das escolhas e das conjunturas específicas que pautam uma dada experiência de vida. Por isso, conforme observa Oliveira (2011), produzir textos biográficos no mundo contemporâneo revela-se um trabalho historiográfico complexo, porque demanda "refazer o caminho que leva à composição da vida de um indivíduo" (OLIVEIRA, 2011, p. 12). Nesses termos, ao trabalhar com fontes documentais e testemunhais, examiná-las, selecioná-las, interpretá-las e escrever sobre a vida de alguém, o biógrafo produz e intermedia informações e conhecimentos de distintas naturezas.

Sendo assim, aos biógrafos competem algumas atitudes clássicas como elucidar a escolha do sujeito a ser biografado, o recorte histórico-metodológico selecionado, as estratégias de reconstrução de certos eventos e biografemas, além de incessante trabalho de investigação documental para desvelar a vida do seu biografado. A tudo isso deve-se acrescentar o cuidado ético e a responsabilidade do pesquisador no momento de compartilhar com familiares, amigos e com o público as informações coletadas, as experiências, os vestígios, os segredos, os sucessos e ou infortúnios das vidas que desvelam. Movimentos que são executados também por aqueles que concebem relatos testemunhais acerca de si mesmos.

Tais singularidades nos permite, pois, apreender as biografias e as autobiografias como "gêneros narrativos específicos" (DOSSE, 2015. p. 66) e, em extensão, defini-las como documentos de memória e fontes de informação. O que pode ser explicado, em ampla medida, pelo fato de homens e mulheres, sabendo-se finitos, intentarem resistir às limitações e fragmentações impostas por Lete ${ }^{4}$ inventando e compartilhando histórias sobre si e sobre os outros. Memória é lembrança e recordação, por seu turno, dizer que o ato de recordar está intrinsecamente interconectado ao gesto narrativo equivale a admitir que a memória se exibe tanto como produto de uma racionalidade particular, quanto como criações e referenciais

\footnotetext{
${ }^{4}$ Nome dado, na mitologia grega, ao mítico rio do submundo que propicia o esquecimento às almas dos mortos.
} InCID: R. Ci. Inf. e Doc., Ribeirão Preto, v. 12, n. 1, p. 82-103, mar./ago. 2021. 
compartilhados socialmente. Atentando para esse duplo movimento, François Hartog (2015, p. 284) pontua:

Não deixa de ser verdade que, durante séculos, o passado foi a categoria de referência,
a categoria dominante. O primeiro movimento era o de olhar para o passado, não para
repeti-lo, mas para compreender o devir, para encontrar seus precedentes, exemplos e
referências, com vistas às ações a serem praticadas. No regime moderno, esse papel
ficou reservado ao futuro, que estabelecia o objetivo a ser atingido e o caminho para
consegui-lo com a maior brevidade possível. A aceleração é um componente do
regime moderno.

Em face disso, na acelerada sociedade atual, sujeitos e grupos convivem com e inventam inúmeras ferramentas destinadas a organizar, preservar e difundir a memória, seja em sua forma documental, seja por meio de testemunhos. Essa condição se tornou ainda mais evidente a partir do grande desenvolvimento das tecnologias de informação e de comunicação que fizeram, segundo Marilena Chauí (2006, p. 140), emergir na cena pública um paradoxo mnêmico: a modernidade valoriza a memória fazendo proliferar artifícios de rememoração tanto pessoais quanto sociais, contudo, essa mesma sociedade, marcadamente encantada pelo novo, desvaloriza a memória em função da manutenção de uma infraestrutura capitalista que sempre precisa se atualizar. Dessa maneira, ao mesmo tempo que se criam museus e outros lugares de memória, cidades são destruídas visando-se "a modernização de seus espaços". Sendo assim, torna-se cada vez mais importante refletirmos acerca dessa problemática, nos indagando sobre a relevância das questões mnêmicas na contemporaneidade para, em seguida, analisarmos os pontos de contato que interconectam as biografias e autobiografias às paragens da memória.

Caminhando nessa direção, sinalizamos que elucidar os vários aspectos que atravessam o ato mnêmico requer conjugar em um mesmo plano analítico referências teóricometodológicas inscritas em campos multidisciplinares do conhecimento como a Literatura, a História, a Antropologia, a Biologia e também aqueles dedicados ao estudo do testemunho e de suas formas de narrativização. Em seu conjunto, esse olhar multidisciplinar demarca que passado e presente encontram-se imbricados à memória, razão pela qual não há como dissociar das experiências individuais os índices de significação subjacentes ao domínio das interações sociais. Tendo por referência essa confluência de olhares, Gondar (2016) estabelece a seguinte proposição acerca dos estudos sobre a memória:

Ainda que possa ser trabalhado por disciplinas diversas, o conceito de memória, mais rigorosamente, é produzido no entrecruzamento ou nos atravessamentos entre diferentes campos de saber. Dito de outro modo: ainda que existam conceitos de memória no interior da filosofia, da psicologia, das neurociências e das ciências da informação, entre outras, a ideia de memória social implica que perguntas provenientes de cada uma dessas disciplinas possam atravessar suas fronteiras, fazendo emergir um novo campo de problemas que até então não se encontrava contemplado por nenhuma delas. (GONDAR, 2016, p. 20-21). 
Nesses termos, do ponto de vista histórico-social, torna-se relevante ressaltarmos que o campo da memória é um terreno conflituoso no qual atuam, de acordo com Jaime Ginzburg, (2013, p. 11-12), elementos de natureza política, ideológica, intelectual e legal empenhados em projetar a "imagem legítima de um passado coletivo", visando-se "controlar, em distintos contextos espaço-temporais, valores, demandas e direitos". Tais contextos podem silenciar, modificar, fazer desacreditar ou apagar muitas histórias de vida. Já assistimos na história, muitos livros proibidos ou queimados pelo poder dominante na tentativa de fazer calar os incômodos. De forma correlata, os lugares de memória nacional constantemente dão-se a ver como empreendimentos que, ao promoverem uma espacialização da memória, exibem um complexo jogo de estratégias em torno da reivindicação de representações por vezes hegemônicas e de baixa assimilação social. Dito em outras palavras, os lugares de memória:

São os resíduos, as marcas, os restos, é porque temos a sensação de que não há memória espontânea que surge a necessidade de criar arquivos, realizar celebrações e escrever atas [...], temos: museus, arquivos, cemitérios, coleções, festas, aniversários, tratados, atas, monumentos, santuários, associações que são criados para testemunhar ilusões de eternidade [...] Os lugares de memória se originam de uma vontade de memória, um desejo de fazer parar o tempo [...]. (BERND, 2013, p. 38-39).

Associado a essa lógica celebrativa, o gesto biográfico pode constituir-se em ars memoriae tanto de uma época, “com seus sonhos e angústias" (DOSSE, 2015, p. 11), quanto de memórias pessoais, familiares, institucionais ou mesmo grupais. Isto porque as biografias e autobiografias constituem-se em empreendimentos narrativos que por meio de uma "articulação entre o individual e o social" (SOUZA, 2009, p. 378) convidam seus leitores a pensarem sobre si mesmos, sobre o outro e sobre o mundo vivido. Soma-se a isso o fato de a história do sujeito biografado estar intimamente imbricada ao "espírito de sua época", razão pela qual toda vida deve ser percebida não como uma sucessão de eventos encadeados cronológica e linearmente, mas, antes, como frutos de escolhas, negociações e contingências que, em seu conjunto, modulam uma imagem razoavelmente delineada de determinado sujeito e de suas experiências vivenciais 5 .

\footnotetext{
${ }^{5}$ Tendo-se em vista clarear ainda mais os pontos de interconexão entre a escrita biográfica e os domínios da memória e do esquecimento, vale citarmos aqui a seguinte passagem de um texto de Leonor Arfuch que busca aproximar as discussões por ela estabelecidas acerca do espaço biográfico com questões concernentes à produção de memórias e testemunhos na contemporaneidade: "Memoria fluctuante, sujeta al vaivén de la temporalidad y no sólo a la pugna con el olvido - por otra parte, su otro constitutivo - que nunca se establece por entero, jaqueada siempre por la aparición de un algo más, huella, revelación, testimonio, prueba. Memoria plural, memorias, apenas pasa de ser un concepto teórico a configurarse en la diversidad narrativa, a expresar tanto la aporía aristotélica de "hacer presente lo que está ausente" como la desconcertante reflexión de Maurice Halbwachs (1992) al formular su concepto de "memoria colectiva": pese a que hay experiencias compartidas por una comunidad, sólo los individuos, las personas, recuerdan. Memorias en plural y, entonces, como terreno de conflicto: la pugna por el sentido de la historia comienza también en su paso inicial; qué es lo que se recuerda,
} 
Portanto, tal como exposto acima, as biografias e autobiografias mantém dupla ligação com as paragens da memória: são documentos históricos e relatos de vidas. É, pois, em função desse duplo estatuto mnêmico que podemos considera-las, também, como fontes de informações gerais e específicas. Elas nos informam sobre as circunstâncias históricas, políticas, culturais e sociais de uma época, tanto quanto sobre as singularidades de uma vida privada, seja ela de pessoas comuns ou daqueles que se tornaram "heróis nacionais" ou, ainda, modelos de virtude. Em outros termos, o potencial informativo e mnêmico das biografias e autobiografias relaciona-se ao fato dessas obras apresentarem os sujeitos biográficos como indivíduos "dotados de uma significativa densidade narrativa sobre suas épocas, ou ainda, como [...] seres humanos dotados de complexas dimensões e relações que estão ligadas aos contextos em que viveram e nos quais suas memórias foram construídas e reconstruídas” (SILVA, 2009, p. 154).

Dessa forma, enquanto obras estruturadas a partir da conjugação de métodos e conceitos multidisciplinares, as biografias e autobiografias manejam e desvelam informações de diferentes naturezas e provenientes de diversas fontes. Condição que nos permite asseverar que, ao adentrarmos no espaço biográfico e ao nos deparamos com uma autobiografia ou uma biografia produzida por terceiro estamos nos colocando diante de obras que, além de fatos, lembranças e informações arranjadas de forma objetiva e/ou linearmente, promovem, segundo a bela expressão de Santo Agostinho (1999), um diálogo entre o tempo do mundo e o tempo da alma.

\section{Biografias e autobiografias como fontes de informação}

Ainda que as sociedades se transformem rapidamente, a informação, tomada como parte integrante da vida social, se mantém enquanto elemento indispensável à promoção do diálogo entre os indivíduos, as organizações e as culturas. Definida por Capurro e Hjorland (2007) como "conhecimento comunicado", a informação confere aos sujeitos, instituições e agrupamentos coletivos a possibilidade de se instruírem, de resolverem problemas gerais e específicos, de produzirem, de compartilharem conhecimentos e de, em face disso, se inserirem e posicionarem-se no mundo. Nesse sentido, nota-se que o registro, a organização, a transmissão

qué es lo que permanece en el flujo del acontecer y accede a la dignidad de la memoria, qué es lo que se silencia, se rechaza o se obnubila. En otras palabras, qué, para quién, para qué”. (ARFUCH, 2014, p. 72-73). 
e a preservação de informações se convertem em preocupações históricas, ganhando acentuada importância econômica e política na contemporaneidade.

Em decorrência da complexificação da vida moderna, sobretudo em razão do rápido desenvolvimento urbano, industrial, tecnológico e comunicacional, somos instigados a acumular todo tipo de informação, estejam elas gravadas em suportes analógicos ou digitais para serem recuperadas posteriormente. Diante da impossibilidade de retermos todas as informações produzidas, o que podemos fazer é recorrer a certas técnicas, recursos e dispositivos que viabilizem acesso rápido, eficaz e confiável aos substratos informacionais que melhor respondam às nossas necessidades específicas. Atentando para isso, Le Coadic (1996, p. 39) afirmou que, contemporaneamente, mais importante que se informar é saber localizar e "usar a informação", ou seja, convertê-la em recurso capaz de racionalizar custos e benefícios, sanar dúvidas e fomentar o aprimoramento e a eficiência das mais diversas instâncias da vida social.

No cerne desses movimentos de busca e uso da informação é natural que, ao nos depararmos com certos conceitos, ideias ou referências que julgamos ininteligível, busquemos ajuda para torna-los mais claros e apreensíveis. Diversas estratégias podem ser empregadas nesse sentido: consultar a alguém de confiança e com um grau de instrução mais avançado, realizar pesquisas em sites da internet ou investigar em uma variedade de outras fontes de informação, sejam elas gerais e/ou específicas, físicas e/ou virtuais.

Ainda que no senso comum a maioria das pessoas não tenha clareza sobre o que venha ser uma "fonte de informação", a interação com elas configura-se, em diferentes momentos e contextos, como uma faceta inerente ao ato de informar-se. Disso se depreende que definir conceitualmente uma fonte de informação implica considerar seus distintos usos em múltiplos campos do conhecimento. Regina Zilberman (2004), por exemplo, assinala que na literatura:

\footnotetext{
Fontes podem ser todo e qualquer material utilizado pelo artista antes de produzir sua obra: lembranças infantis, sonhos, histórias particulares ou coletivas, a tradição local ou nacional, escritos próprios ou alheios. Genericamente, fontes corresponde a um significante que pode acolher tudo que precede a obra, pertencendo à sua fase de gestação e produção. Atribuir-lhe esse significado, porém, não basta; de um lado, por se mostrar muito abrangente; de outro, por não levar em conta escolhas do pesquisador que deseja privilegiar o estudo das fontes (ZILBERMAN, 2004, p. 18).
}

Da forma como foi elaborado, esse conceito de fonte engloba todos os instrumentos necessários para que um autor/artista realize sua obra. Na prática, portanto, essas fontes podem ser definidas como material de referência - histórica, política, geográfica, artística, estética, 
informativa, etc. - porque foram capazes de conferir a esse trabalho in progress "um arranjo e um significado" (ZILBERMAN, 2004, p. 18).

Colocado nesses termos, definir uma fonte de informação significa, entre outras ações, observar a especificidade das informações que elas agregam - razão pela qual podem ser classificadas como primárias, secundárias ou terciárias - a forma como essas informações são divulgadas - de forma corrente ou restrita - e o potencial uso que delas será feito. Contextualização prévia que revela, de imediato, que cada fonte de informação possui uma origem e uma funcionalidade demarcada e, também, que o modo como a informação é registrada e/ou difundida acaba por lhe agregar valor social e definir tanto a natureza dos conhecimentos por ela congregados quanto os contornos de sua aplicação nas muitas instâncias de produção e uso dos saberes às quais se aplicam.

À vista disso e tendo por referência uma dimensão generalista, as fontes de informação podem ser agrupadas em: enciclopédias, dicionários, fontes biográficas, fontes geográficas, meios de comunicação como jornais, televisão, sites na internet, entre outros. Não obstante, existem as fontes de informação especializadas, aquelas que são destinadas a prover informações específicas para sujeitos inscritos em diferentes ramos da produção social do conhecimento.

Conforme dissemos acima, em termos operacionais, é comum que as fontes de informação sejam classificadas em fontes primárias, secundárias e terciárias. Na primeira categoria estão inscritas fontes tidas como originais, "aquelas produzidas com a interferência direta do autor da pesquisa" (MUELLER, 2000, p. 31). Logo, citamos, entre outros, os manuscritos, os rascunhos de um livro, dissertações, teses, relatórios técnicos, patentes, as escritas de si, diários, cartas, entrevistas inéditas, discursos, testamentos e, atualmente, as correspondências eletrônicas. Por vezes essas fontes encontram-se dispersas em arquivos pessoais ou públicos, pressupondo, para sua utilização e difusão, um rigoroso trabalho de pesquisa, identificação, coleta e organização.

Já as fontes secundárias se organizam em torno de documentos primários, contribuindo, assim, para a localização das fontes primárias. O resultado desse movimento se dá a ver sob a forma de "um resumo, de uma seleção especializada ou de um catálogo coletivo" (CUNHA; CAVALCANTI, 2008, p. 172), bem como em um dicionário, enciclopédia, revisões de literatura, filmes, vídeos, biografias, base de dados, artigos de revisão, entre outros. Além disso 
faz-se necessário destacar que as fontes secundárias sofrem a influência daqueles que as organizam, indicando uma interpretação e avaliação prévia dos documentos primários.

No que diz respeito às fontes terciárias, além de variadas, é possível se apontar que elas são constituídas a partir da reunião das fontes primárias e secundárias, dando origem às bibliografias, aos serviços de indexação e resumos, aos guias de obras de referência, aos catálogos coletivos, aos guias de literatura, aos diretórios, almanaques, entre outras. Em decorrência da tipologia de informações que agenciam, as fontes terciárias são as mais complexas de serem estabelecidas, elaboradas e definidas, sendo geralmente identificadas como "aquelas que têm a função de guiar o usuário para as fontes primárias e secundárias" (MUELLER, 2000, p. 32).

Complementar a essa classificação, existem aquelas fontes que estão disponíveis apenas na Internet e que abrangem tanto "fontes primárias, secundárias e terciárias, quanto novas fontes construídas especificamente para o meio eletrônico" (PINHEIRO, 2006, p. 35).

Nos campos da Biblioteconomia e da Ciência da Informação muitos autores segmentam as fontes de informação em modalidades específicas com vistas a contemplar certas particularidades de determinados ramos do conhecimento. Isso assinala, segundo (PINHEIRO, 2006, p. 2), certa "analogia com o conceito de "literatura de", adotado pela Ciência da Informação, relativo à produção científica de determinada área ou mesmo de "fonte primária", na História". Nesse sentido, são ordenadas tendo por referência o direcionamento a um assunto, congregando em um mesmo universo informacional dados e insumos de conhecimento coletados em fontes de natureza científica, tecnológica, cultural, para negócios, jurídica e financeira, independente dessas informações estarem registradas em livros, periódicos científicos, monografias, teses e dissertações, artigos de revisões de literatura, resumos, índices e outras bibliografias, anais de eventos científicos e/ou outras bases de dados.

Como as modalidades de uso de uma fonte de informação impactam diretamente em sua classificação, faz-se evidente que o trabalho de identificação e de definição de critérios capazes de validar a pertinência de uma fonte para determinada pesquisa ou para sanar uma necessidade específica envolve muitos profissionais com conhecimento prévio. Por conseguinte, tais qualificadores se dão a ver como um trabalho colaborativo que articula acervos multivariados, modalidades de compreensão que podem ser facilmente observadas a partir do quadro abaixo: 
Quadro 01 - Tipologia e classificação das fontes de informação

\begin{tabular}{|c|c|c|}
\hline $\begin{array}{c}\text { CLASSIFICAÇÃO } \\
\text { DAS FONTES }\end{array}$ & CARACTERÍSTICAS & EXEMPLOS \\
\hline PRIMÁRIAS & $\begin{aligned} & \text { Registram informações no } \\
& \text { momento de sua } \\
& \text { publicação, no corpo de } \\
& \text { conhecimento científico e } \\
& \text { tecnológico; } \\
&> \text { Informação original, } \\
& \text { protagonismo, o } \\
& \text { pensamento original do } \\
& \text { autor e o seu } \\
& \text { compartilhamento; } \\
&> \text { Proximidade com a fonte } \\
& \text { original; } \\
&> \text { Novas evidências sobre o } \\
& \text { assunto; } \\
&>\text { Dispersas em sua } \\
& \text { localização. }\end{aligned}$ & 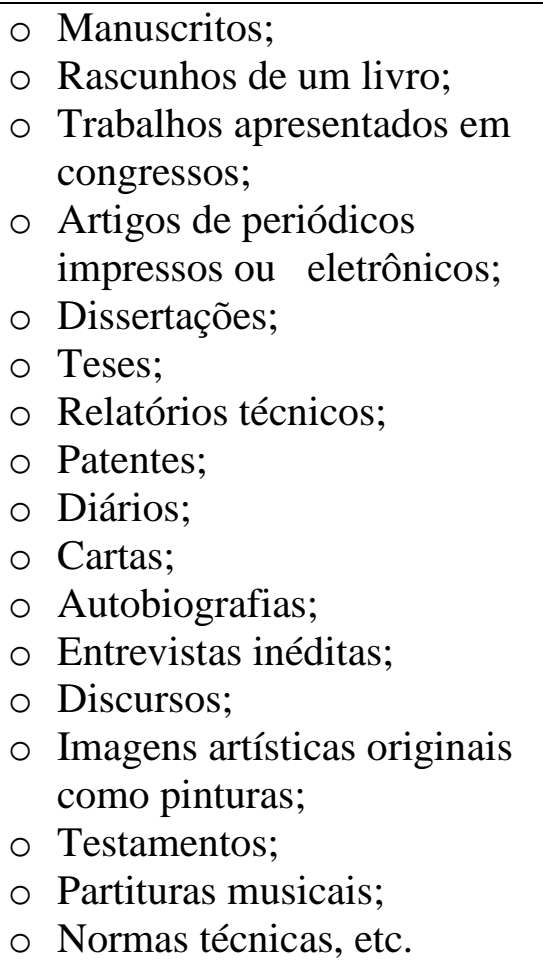 \\
\hline SECUNDÁRIAS & $\begin{array}{l}\text { Contêm informações } \\
\text { sobre documentos } \\
\text { primários e orientam o } \\
\text { usuário na sua pesquisa; } \\
\text { Sofrem a influência } \\
\text { daqueles que interpretam } \\
\text { e avaliam as fontes } \\
\text { primárias; } \\
\text { Colabora para a } \\
\text { localização das fontes } \\
\text { primárias. }\end{array}$ & 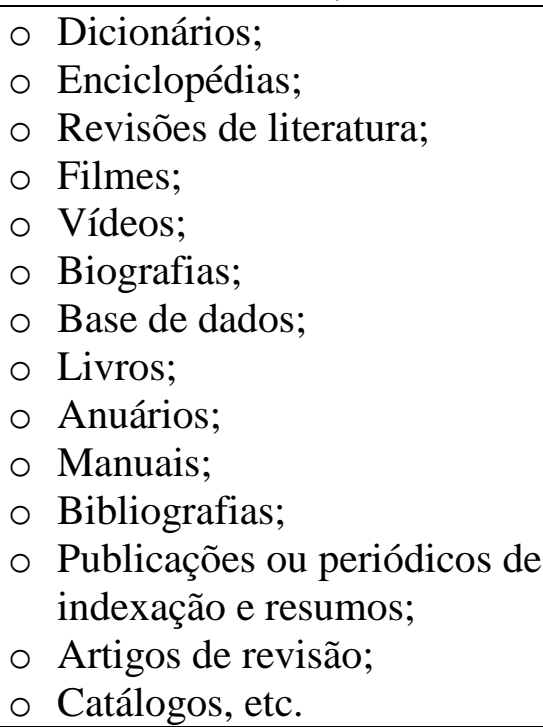 \\
\hline TERCIÁRIAS & $\begin{array}{l}\text { Constituem-se na reunião } \\
\text { das fontes primárias e das } \\
\text { fontes secundárias; } \\
\text { São complexas em sua } \\
\text { elaboração; } \\
\text { Guiam os usuários às } \\
\text { fontes primárias e } \\
\text { secundárias. }\end{array}$ & $\begin{array}{l}\text { Bibliografias; } \\
\text { Serviços de indexação e } \\
\text { resumos; } \\
\text { Oatálogos coletivos; } \\
\text { O Guias de literatura; } \\
\circ \text { Diretórios (ex: guias de } \\
\text { museu, páginas amarelas das } \\
\text { listas de telefone); } \\
\text { - Almanaques, etc. }\end{array}$ \\
\hline
\end{tabular}

Fonte: Elaborado pelos autores 
Uma vez definidas e caracterizadas as especificidades das 3 (três) principais tipologias de fontes de informação, convém reforçar, agora, os atributos conceituais e funcionais que convertem as fontes biográficas em fontes de informação e de memória.

Tendo isso como eixo norteador, vale lembrarmos que, enquanto obras inscritas em tempos e espaços específicos, as biografias e autobiografias respondem e dão a ver os interesses e querelas de sua época, tanto em relação ao método empregado na construção de sua narrativa, quanto em termos da escolha daquele que será biografado. Em função disso, podemos dizer que esses dados sociais, culturais e históricos já comprovam, por si só, os atributos informacionais das fontes biográficas. Contudo, podemos ir além e pontuarmos que essas obras são realizadas a partir de amplos processos de pesquisa e sistematização de informações captadas em várias outras fontes e documentos, circunstâncias que nos impelem a evocarmos outra vez mais as seguintes questões: que elementos caracterizam uma escrita biográfica? Que atributos fazem das biografias e autobiografias fontes de informação e memória? Peter Burke nos ajuda a lançar luzes sobre essas indagações ao acentuar que:

O termo biographia foi cunhado na Grécia no fim do período antigo. Antes disso, falava-se em escrever "vidas" (bioi). Em sua biografia de Alexandre o Grande, Plutarco faz uma distinção importante entre escrever história narrativa e escrever "vidas", como ele mesmo estava fazendo. Nas "vidas" havia espaço para abordar tanto a esfera privada quanto a pública, para descrever a personalidade individual através de pequenas pistas, "algo pequeno como uma frase ou um chiste" [...] Montaigne também enfatizou a afirmação de Plutarco de que gestos aparentemente banais oferecem pistas sobre a personalidade (BURKE, 1997, p. 89-90).

Sem descredenciar os trabalhos de Plutarco e Montaigne, Philippe Lejeune observa que, na atualidade, o termo biografia pode ser empregado para nomear textos com distintos objetivos, sendo os mais comuns aqueles que versam sobre:

1) a história de um homem (em geral célebre) escrita por outrem (é o sentido antigo e mais comum); 2) a história de um homem (em geral obscuro) contada oralmente por ele próprio a outra pessoa que o levou a empreender essa narrativa para estuda-la (é o método biográfico das ciências sociais); e 3) a história de um homem contada por ele próprio a outra ou outras pessoas que o ajudam, com sua escuta, a se orientar na vida (é a (auto) biografia feita no âmbito da formação) (LEJEUNE, 2014, p. 6162).

Na citação acima, o termo “(auto) biografia” foi utilizado por Lejeune para se referir à vida de um indivíduo escrita por ele mesmo. Acepção ampliada pelo autor ao descrever as intricadas tramas que amparam o pacto autobiográfico. Mais que um relato memorialístico ou confessional, a escrita autobiográfica se expressa por meio de "qualquer texto em que o autor parece expressar sua vida ou os seus sentimentos, quaisquer que sejam a forma do texto e o contrato proposto por ele" (LEJEUNE, 2014, p. 53). Contrato este que, por sua vez, se expressa 
por meio de uma sinuosa rede de relações tecida entre o autor, o narrador e o personagem biográfico.

Ao converter vidas privadas em narrativas literárias, ensaios históricos ou textos de divulgação, as biografias e autobiografias tornam-se objetos de estudos e fontes documentais em distintas áreas do conhecimento, conjuntura marcadamente vinculada, entre outros aspectos, aos fatos dessas obras se apresentarem como "lócus privilegiado de construção da memória pessoal, local e nacional e, portanto, de experimentação (auto)biográfica" (CARVALHO, 2008, p. 22).

No contexto da Biblioteconomia e da Ciência da Informação elas são investigadas e apreendidas como fontes documentais voltadas à divulgação de informações primárias e/ou secundárias acerca do sujeito ou da instituição biografada. É nesse sentido, pois, que as narrativas biográficas podem ser tratadas como fontes informacionais subscritas e amparadas por outras fontes documentais que são analisadas e interpretadas por aqueles que objetivam narrar uma vida. Em face disso, ao articularem um conjunto multidisciplinar de conhecimentos, as fontes biográficas se aproximam do gênero histórico-literário que as diferenciam "da simples informação biográfica sobre um indivíduo [data de nascimento e morte, por exemplo], em termos de conteúdo, finalidade e estilo”, (VIANNA; MARQUES JUNIOR, 2005, p. 44), propiciando a apreensão e difusão de conhecimentos que transpõem em muito "informações factuais sobre uma pessoa". Atributos também acentuados por Carvalho (2008, p. 23) ao esclarecer que:

Fonte de alimentação de outras fontes, a chamada fonte primária recusa o sentido
pejorativo de elementar, rudimentar, para evocar o sentido de fonte primeira onde o
sentido flui livremente, não está congelado, jorra continuadamente novas
configurações. É ponto primeiro mas, ao mesmo tempo, ponto relacional, lançando e
deslocando explicações. Dito de outra maneira, o ponto relacional ou em relação
sugere movimento à medida que possibilita a abertura explicativa de um texto final,
ou de um objeto. Tal abertura possibilita, ao mesmo tempo, a explicação da própria
fonte tornada texto (CAMPOS; CURY, 1997). Ou ainda, como Arlette Farge (1989,
p.12), ao buscar o conteúdo semântico da expressão fonte, é possível recuperar a ideia
de mergulho, por vezes de afogamento, de submersão em busca do ponto de origem,
ponto primacial por excelência, aquele que antecede o primeiro.

Assim observado e em decorrência da natureza híbrida das fontes biográficas, além de informações sobre o ciclo vital do sujeito biografado, o leitor quase sempre se deparará com dados históricos e geográficos que dizem sobre uma época ou um lugar específico, formulações estéticas ou filosóficas que versam sobre a concepção de uma obra ou uma teoria, e, também, marcadores referentes a certas relações institucionais, culturais e pessoais fundamentais para se delinear os rumos tomados por determinada trajetória de vida. 
Embora congregue tais potencialidades, é importante frisar que o usuário de uma fonte biográfica também possui papel ativo no processo de "filtragem" das informações por elas agenciadas. À vista disso, como acontece com qualquer outra fonte de informação, o interesse pelas fontes biográficas se evidencia por meio de fatores de ordem tanto prática - descobrir datas ou clarear certos acontecimentos da vida daquele que foi biografado -, quanto a motivos mais personalistas como a curiosidade ou o apreço pela história privada - amores, desavenças, grandes acontecimentos - de certa personalidade e até mesmo às condições históricas, políticas, culturais e institucionais que possibilitaram a formulação de uma nova teoria ou uma notável descoberta. Congregados entre si, esses elementos nos permitem asseverar que as biografias e autobiografias são classificadas como fontes de informação porque:

\begin{abstract}
A informação sobre a vida das pessoas está relacionada a todas as áreas do desempenho humano e constitui demanda constante em todos os tipos de bibliotecas e centros de informação especializados. [...] A biografia pode servir como recurso para obtenção de informações as mais diversas possíveis, sobre um período histórico, uma nação, uma instituição etc. [...] Podem ser considerados dois grupos principais: as autobiografias e as biografias [...] Entretanto, as autobiografias propriamente ditas são o relato verdadeiro de revelações feitas por um indivíduo em determinado momento da sua trajetória. Diferenciam-se das memórias porque ao ultrapassarem o simples relato de acontecimentos significativos, traduzem a essência do pensamento de seu autor, [...] que pode ser permeada de omissões e/ou distorções feitas de forma consciente ou inconsciente (VIANNA; MARQUES JUNIOR, 2005, p. 43-45).
\end{abstract}

A esses aspectos devemos acrescentar os argumentos de François Dosse, segundo os quais o que realmente importa ter em vista quando se toma contato com um relato autobiográfico é:

Saber que lugar será conferido a essa escrita do eu, por muito tempo indiferenciada da escrita do outro. [...] O uso de memórias, confissões ou registros autobiográficos adotados de formas diversas nas biografias dá a entender que se está mais próximo da restituição autêntica do passado (DOSSE, 2015, p. 68).

Essa escrita exige, portanto, que seja estabelecido por parte daquele que narra uma vida - a dos outros ou a sua própria - um pacto autobiográfico, ou seja, um tipo de contrato de comunicação ${ }^{6}$. Isso se estabelece porque, ao mesmo tempo em que recolhem e selecionam acontecimentos individuais e coletivos, relações políticas, econômicas, culturais e sociais, as biografias resgatam vidas, evidenciam falas, pontuam imagens e visões de mundo que, trazidas a público, além de ganharem evidência se mostram sujeitas a toda sorte de interpretações.

\footnotetext{
${ }^{6}$ Referência ao conceito desenvolvido pelo linguista francês Patrick Charaudeau (1996), para quem nossas práticas comunicativas pressupõem um conjunto de condições às quais incidem sobre a estruturação e realização das narrativas que emergem dessas práticas interacionais.
} 
Sendo assim, as abordagens contemporâneas da biografia preconizam um trabalho consistente e cuidadoso de cunho interpretativo e a consolidação de conhecimentos interdisciplinares, o que exige do pesquisador/biógrafo maior atenção ao lidar com a massa de informações por ele coletada. Diretivas que se tornaram ainda mais complexas nos dias atuais, sobretudo em decorrência das inovações tecnológicas e do apagamento, no mundo digital, de importantes vestígios biográficos como rascunhos, manuscritos, anotações pessoais, diários eletrônicos, entre outros. Um comentário esclarecedor acerca dessa questão nos é oferecido por Walter Isaacson, biógrafo de Leonardo da Vinci, que logo na abertura de sua narrativa pontua:

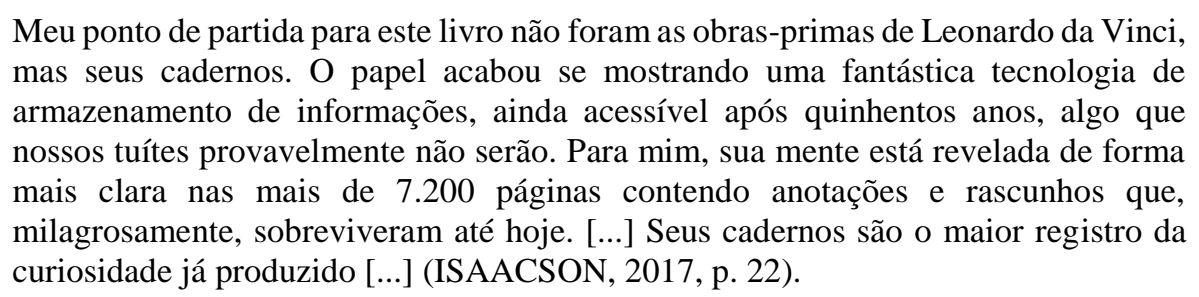

Essa afirmativa deixa mais claro que por meio dos fatos, relatos e cenas entrelaçados por uma fonte biográfica nos tornamos capazes de conhecer melhor o percurso de uma vida e, também, de compreendermos mais claramente os detalhes acionados em outros contextos espaço-temporais para caracterizar dado sujeito como extraordinário e a sua obra como expressão da genialidade humana. Transpondo a esfera acadêmica, esses mesmos indícios esclarecem o grande interesse histórico, por parte do público em geral, pelos relatos biográficos, sejam eles de pessoas notáveis ou de homens e mulheres anônimas.

Talvez seja em função disso que, como vimos acima, ao biografar Leonardo da Vinci, Isaacson não se ocupou apenas em justapor fatos e enumerar acontecimentos capazes de descrever a vida do polímata renascentista. Mais que isso, ao estudar longamente as mais de 7.200 páginas que compõem seus cadernos de anotações, o biógrafo acabou por estabelecer uma conexão entre o "pensar e o existir" de Leonardo, alcançando, com isso, nos dizeres de François Dosse (2015, p. 364), "uma unidade entre o racional e o existencial”.

Esse argumento nos permite reafirmar que as fontes biográficas, além de congregarem em torno de si inúmeros outros conceitos, cujos principais são informação e memória, suprem, enquanto obras de referência, as necessidades informacionais de sujeitos vinculados a uma multiplicidade de áreas do conhecimento, daí podermos falar em biografia musical, biografia artística, biografia política e biografia intelectual. Além disso, a autenticidade dos documentos consultados e a veracidade das informações que fornecem configuram-se como elementos que 
devem ser considerados quando o que se deseja é demarcar o potencial informativo dessas obras.

Portanto, se nosso objetivo era caracterizar as biografias e autobiografias como fontes de informação e memória, podemos ratificar a validade dessa argumentação assinalando que além de organizarem um amplo conjunto de informações e documentos que nem sempre estão à disposição do grande público, as biografias e autobiografias também são capazes de suscitarem novos trabalhos de pesquisa, tornando mais claras - uma vez que lidam com a densidade social, histórica e intersubjetiva de memórias e vivências singulares - as contingências de uma vida e as especificidades do tempo e do espaço no qual ela transcorreu e adquiriu sentido.

\section{Considerações finais}

O levantamento histórico-conceitual aqui realizado demonstrou a longa duração do gênero biográfico. Concomitantemente, ao assinalar as rupturas epistemológicas concernentes aos seus processos evolutivos, tornou mais clara sua importância enquanto fonte de informação e memória para as ciências humanas e sociais, a literatura e os estudos informacionais. Razão pela qual destacamos o tratamento multidisciplinar que lhe é conferido pelos mais variados campos do conhecimento.

No âmbito dos estudos informacionais, especialmente na Biblioteconomia, essas obras são classificadas como fontes de informação, ou seja, como documentos que difundem informações primários ou originais - no caso das autobiografias - ou como fontes secundárias - no caso das biografias - cujo valor documental dá a ver o denso trabalho de pesquisa levado a cabo por profissionais que investigam e coletam informações em diários, cartas, memórias, rascunhos e originais de certas obras ou em entrevistas e depoimentos concedidos tanto pelo sujeito biografado quando por quem com ele travou contato.

Com isso, ao serem coligidas, organizadas e ganharem certa estrutura narrativa, essas fontes informam aos seus leitores sobre as circunstâncias históricas, políticas, culturais e sociais de uma época, tanto quanto sobre as singularidades de uma vida privada, seja ela de pessoas comuns ou daqueles que se tornaram "heróis nacionais" ou mesmo modelos de virtude. Em face disso, acreditamos estar claro que, muito mais que obras literárias, as fontes biográficas são, por diferentes aspectos e atributos, fontes de informação e de memória que dizem muito - que 
agenciam, mobilizam e fazem circular - informações de distintas naturezas, tanto quanto referências mnêmicas e testemunhais sobre determinado período histórico, a sociedade e a cultura e também sobre os indivíduos, seus sonhos, idiossincrasias, escolhas e relações sociais.

\section{Referências}

AGOSTINHO, Santo. O homem e o tempo. In: AGOSTINHO, Santo. Confissões. São Paulo: Nova Cultural, 1999. p. 309-340. (Os Pensadores).

ARFUCH, Leonor. (Auto)biografía, memoria e historia. Clepsidra: Revista Interdisciplinaria de Estudios sobre Memoria, Buenos Aires, n. 1, marzo 2014, p. 68-81.

ARFUCH, Leonor. O espaço biográfico: dilemas da subjetividade contemporânea. Rio de Janeiro: Universidade do Estado do Rio de Janeiro, 2010.

BERND, Zilá. Por uma estética dos vestígios memoriais: releitura da literatura contemporânea das Américas a partir dos rastros. Belo Horizonte: Fino Traço: 2013.

BURKE, Peter. A invenção da biografia e o individualismo renascentista. Revista Estudos Históricos, Rio de Janeiro, v. 10, n. 19, p. 83-98, jul. 1997. Disponível em: https://bibliotecadigital.fgv.br/ojs/index.php/reh/article/view/2038/1177. Acesso em: 06 maio 2018.

CAMPELLO, Bernadete Santos; CENDÓN, Beatriz Valadares; KREMER, Jeannette Marguerite. (org.). Fontes de informação para pesquisadores e profissionais. Belo Horizonte: Editora UFMG, 2000.

CAPURRO, Rafael; HJORLAND, Bieger. O conceito de informação. Perspectivas da Ciência da informação, Belo Horizonte, v. 12, n. 1, jan./abr. 2007. Disponível em https://www.scielo.br/scielo.php?script=sci_arttext\&pid=S1413-99362007000100012. Acesso em: 24 nov. 2020

CARVALHO, Maria da Conceição. Cordialmente, Eduardo Frieiro: fragmentos (auto) biográficos. 2008. 366f. Tese (Doutorado em Letras) - Faculdade de Letras da Universidade Federal de Minas Gerais, Belo Horizonte, 2008.

CHARAUDEAU, Patrick. Para uma nova análise do discurso. In: CARNEIRO, Agostinho Dias (org.). O discurso da mídia. Rio de Janeiro: Oficina do autor, 1996. p. 5-44.

CHAUÍ, Marilena. Convite à filosofia. São Paulo: Ática, 2006.

COSTA, Luciano Bedin da. Biografema como estratégia biográfica: escrever uma vida com Nietzsche, Deleuze, Barthes e Henry Miller. 2010. 180f. Tese (Doutorado em Educação) Faculdade de Educação da Universidade Federal do Rio Grande do Sul, Porto Alegre, 2010.

CUNHA, Murilo Bastos; CAVALCANTI, Cordélia Robalinho de O. Dicionário de biblioteconomia e arquivologia. Brasília: Briquet de Lemos, 2008. 
GONDAR, Jô. Cinco proposições sobre memória social. Revista Morpheus: estudos interdisciplinares em Memória Social, Rio de Janeiro, v. 9, n. 15, p. 19-40, 2016. (Edição Especial: Por que memória social?). Disponível em:

http://www.seer.unirio.br/index.php/morpheus/article/view/5475. Acesso em: 23 nov. 2020.

DOSSE, François. O desafio biográfico: escrever uma vida. São Paulo: EDUSP, 2015.

GINZBURG, Jaime. Prefácio. In: BERND, Zilá. Por uma estética dos vestígios memoriais: releitura da literatura contemporânea das Américas a partir dos rastros. Belo Horizonte: Fino Traço, 2013. p. 11-12.

HARTOG, François. Entrevista concedida a Mariza Romero. Revista Brasileira de História. São Paulo, v. 35, n. 70, July/Dec. 2015. Disponível em

https://www.scielo.br/scielo.php?pid=S0102-01882015000200281\&script=sci_arttext Acesso em: 17 mar 2019.

ISAACSON, Walter. Leonardo da Vinci. Rio de Janeiro: Intrínseca, 2007.

LE COADIC, Yves-François. A ciência da informação. Brasília: Briquet de Lemos, 1996.

LE GOFF, Jacques. São Luís: biografia. 5. ed. Rio de Janeiro: Record, 2014.

LEJEUNE, Philippe. O pacto autobiográfico: de Rousseau à internet. Belo Horizonte: UFMG, 2014.

LORIGA, Sabina. O pequeno X: da biografia à história. Belo Horizonte: Autêntica, 2011.

MOLLOY, Sylvia. Vale o escrito: a escrita autobiográfica na América Hispânica. Chapecó: Argos, 2003.

MUELLER, Suzana Pinheiro Machado. A ciência, o sistema de comunicação científica e a literatura científica. In: CAMPELLO, Bernadete S; CENDÓN, Beatriz Valadares; KREMER, Jeannette Marguerite. (org.). Fontes de informação para pesquisadores e profissionais. Belo Horizonte: Editora UFMG, 2000. p. 21-34

OLIVEIRA, Maria da Glória de. Escrever vidas, narrar a história: a biografia como problema historiográfico no Brasil oitocentista. Rio de Janeiro: FGV, 2011.

PINHEIRO, L. V. R. Fontes ou recursos de informação: categorias e evolução conceitual. Pesquisa Brasileira em Ciência da Informação e Biblioteconomia, João Pessoa, v. 1, n. 1, 2006. Disponível em: https://periodicos.ufpb.br/index.php/pbcib/article/view/8809/4716. Acesso em: 24 nov. 2020.

SCHMIDT, Benito Bisso (org.). O biográfico: perspectivas interdisciplinares. Santa Cruz do Sul: EDUNISC, 2000.

SILVA, Sheila dos Santos; MOREIRA, Maria Elisa Rodrigues. Escritas de si e espaço biográfico: revisão teórico-crítica. MEMENTO: Revista de Linguagem, Cultura e Discurso Mestrado em Letras, Departamento de Letras - UNINCOR, Três Corações, n. 2, p. 1-19, jul./dez., 2016. Disponível em: http://periodicos.unincor.br/index.php/memento/article/view/3780/2788. Acesso em: 24 nov. 2020. 
SILVA, Wilton Carlos Lima da. Biografias: construção e reconstrução da memória.

Fronteiras: Revista de História - PPGH/FCH/UFGD, Dourados, v. 11, n. 20, p. 151-166, jul./dez. 2009.

SOUZA, Eneida Maria de. Modernidades alternativas na América Latina. Belo Horizonte: Editora UFMG, 2009.

STAROBINSKI, Jean. Jean-Jacques Rousseau: a transparência e o obstáculo. São Paulo: Companhia da Letras, 2011.

VIANNA, Márcia; MARQUES JR., Alaor. Fontes biográficas. In: CAMPELLO, Bernadete; CALDEIRA, Paulo da Terra. Introdução às fontes de informação. Belo Horizonte: Autêntica, 2005. p. 43-51.

ZILBERMAN, Regina et al. As pedras e o arco: fontes primárias, teoria e história da literatura. Belo Horizonte: UFMG, 2004. 